\title{
Apontamentos de anatomia e fisiologia da lactação
}

Adelaide Órfão,* Cristina Gouveia**

\section{RESUMO}

O tamanho das mamas está relacionado com a quantidade de tecido mamário e depósitos de gordura intra e inter lobular, mas não reflecte a sua capacidade funcional.

As principais hormonas que regulam a produção de leite são a prolactina, a oxitocina e o FIL (factor inibidor da lactação). Preocupações como o medo de não ter leite suficiente inibem a oxitocina e dificultam a lactação.

O lactente pode regular a composição do leite obtido se puder modificar três factores: o tempo de intervalo entre as sucessivas mamadas, o volume de leite ingerido de cada vez e o acesso livre ao leite produzido por uma só mama ou nas duas.

De acordo com os estudos observacionais mais recentes, o RN de termo, saudável, quando colocado sobre o abdómen da mãe, desloca-se de forma reflexa e adapta-se autónoma e perfeitamente a uma das mamas sem causar qualquer desconforto/dor à mãe. Este comportamento autónomo do bebé parece ainda estar associado a um maior grau de satisfação materna e prolongamento da amamentação.

Dada a especificidade de cada díade mãe-bebé a gestão pelo cliente parece ser a resposta chave para o sucesso do aleitamento materno.

Palavras-chave: Anatomia; Fisiologia; Glândula Mamária; Gestão da Lactação.

\section{INTRODUÇÃO}

A pesar da escassez de documentos acredita-se que, desde tempos imemoriais até ao início do séc. XX, o aleitamento Materno (AM) tenha sido encarado como o alimento próprio para os bebés e crianças sem que sobre isso se levantassem dúvidas. Em 1905, mesmo nos países europeus industrializados, estaria preconizado o aleitamento materno em regime de exclusividade até aos 12 meses, mantendo-se como alimento principal das crianças pequenas nos primeiros anos de vida.

As sucessivas revoluções industriais, a expansão dos mercados, a I e II Guerra Mundial, a luta contra pandemias como a peste ou a tuberculose, a emancipação das mulheres, a massificação da contracepção e o eclodir do Marketing têm de alguma forma vindo a ser associados ao declínio da cultura do AM. ${ }^{1}$ No entanto, no nosso país, todas estas revoluções da modernidade foram sendo filtradas e tendo um impacte diferente.

Portugal tem ainda na sua memória recente a amamentação como modo natural de alimentar os bebés.

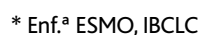

**Pediatra, IBCLC
}

De acordo com as estatísticas disponíveis, à data da alta hospitalar a larga maioria das puérperas e seus recém-nascidos terão como plano alimentar esperado o aleitamento materno exclusivo, o que permite falar numa taxa de $90 \%$ de iniciação., ${ }^{2,3}$

A maioria dos profissionais conhece as recomendações internacionais e é favorável ao aleitamento materno considerando-o como a melhor forma de alimentar os bebés, sempre que possível.

Assim, quando em dado momento da estadia hospitalar são superadas as dificuldades iniciais e um recém-nascido amamentado dá mostras de ficar satisfeito, temos tendência a acreditar que mãe e filho terão sucesso. Ainda que o bebé em causa tenha recebido leite materno uma única vez, queremos acreditar que a tendência será para melhorar.

No entanto, a elevada taxa de aleitamento materno exclusivo à alta $^{3}$ (que apenas significa que no momento da alta não foi prescrita suplementação) parece ter um acentuado declínio logo no primeiro mês de vida para ser de apenas $50 \%$ aos 3 meses. ${ }^{4}$

Diversos trabalhos (conhecedores dos factores da modernidade já referidos) têm procurado analisar as causas do «abandono precoce» e referem resultados 
como: leite insuficiente, pouco leite, choro do bebé e cansaço materno, associados a uma má progressão do peso, ou: bloqueio dos ductos, ingurgitamento mamário, mastite e exaustão materna, com igual má progressão do peso. Quer se relacionem com a «escassez de leite» ou com o seu «excesso» ambas as situações parecem ter em comum queixas como fissuras mamilares, utilização de mamilos silicone e extracção mecânica do leite..$^{5}$ Consensualmente, os estudos apontam o apoio às mães na resolução das dificuldades dos primeiros dias como estratégia primordial para o prolongamento da amamentação. A actualização dos conhecimentos sobre anatomia e fisiologia da lactação tornou-se fundamental uma vez que nas últimas décadas a investigação científica específica tem sido profícua.

Os motivos que levaram ao declínio das taxas de aleitamento incluem a falta de interesse e o desconhecimento dos profissionais. ${ }^{6}$ Segundo King, ${ }^{7}$ a falta de apoio dos serviços hospitalares e o facto dos profissionais que trabalham nos Centros de Saúde não saberem como orientar as mulheres sobre os problemas na amamentação constituem factores determinantes do insucesso. $^{3}$

Como a promoção do aleitamento materno constitui uma medida de saúde pública com francos benefícios de saúde para mães e bebés, é importante capacitar médicos, enfermeiros e outros com os conhecimentos de lactação necessários, para apoiar as mães para que possam corresponder ao seu próprio projecto, prolongar a amamentação e obter maiores ganhos em saúde para si e para os seus filhos.

\section{ANATOMIA E FISIOLOGIA}

As mamas ${ }^{a}$ são estruturas anexas à pele especializadas na produção de leite. Existem em ambos os sexos mas são rudimentares nos homens. Nas mulheres desenvolvem-se e diferenciam-se na puberdade, atingindo o seu maior desenvolvimento na gravidez e na lactação. Composto pelas células produtoras de leite, $63 \%$ do total, o tecido glandular está na sua maioria localizado a cerca de $3 \mathrm{~cm}$ da base do mamilo. $\mathrm{O}$ tecido adiposo distribui-se imediatamente abaixo da pele (tecido adiposo subcutâneo), no interior da glândula mamária (intra-glandular) e atrás do tecido glandular (retro-ma-

a. E não seios, que anatomicamente referem cavidades ou bolsas. mário) à frente do músculo peitoral. O tecido subcutâneo na base do mamilo é mínimo. Situadas entre as camadas superficial e profunda da pele, as mamas estendem-se entre a segunda e a sexta costelas e do esterno à linha axilar média.

Quanto à sua forma podem ser hemisféricas, cónicas, piriformes, cilíndricas ou discóides. São ligeiramente assimétricas e estão separadas pelo sulco intermamário e limitadas inferiormente pelo sulco inframamário (que, de acordo com a idade ou estado funcional, pode apresentar-se mais ou menos profundo).

Os ácinos ou alvéolos mamários, unidades ultraestruturais da glândula mamária, são constituídos por células secretoras rodeadas por tecido mioepitelial. Estão organizados em 7 a 10 lobos que se dividem em lóbulos e estão separados por septos fibrosos (ligamentos de Cooper) que se estendem da faixa profunda à pele. O tecido conjuntivo interlobular contém depósitos de adipócitos (Figura 1). Cada um dos seus ductos excretores termina de forma independente no mamilo. Por serem revestidos por uma camada de células mioepiteliais, os ductos são igualmente sensíveis à acção da oxitocina, reagindo com «movimentos peristálticos» que contribuem na ejecção do leite.

O mamilo ou papila mamária é constituído por fibras musculares lisas, é proeminente, cilíndrico e circundado por uma zona mais escura de tamanho variável e pele pigmentada que pode apresentar alguns pêlos,

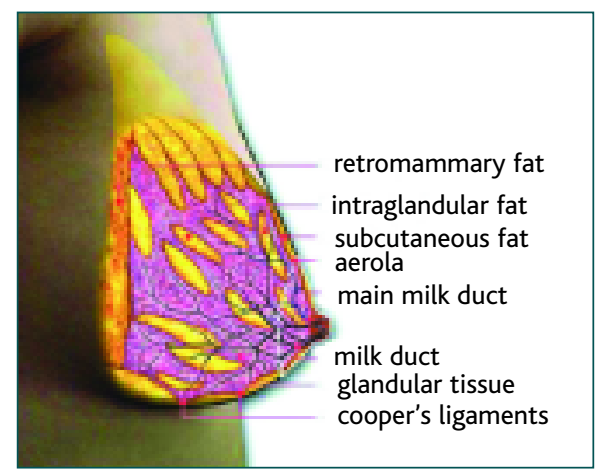

Figura 1. Anatomia da mama/OMS - Curso Formação de Formadores em Aleitamento Materno ARS Algarve 2007 Blackwell Publishing, Ltd.

Ramsay DT, Kent JC, Hartmann RA, Hartmann PE. Anatomy of the lactating human breast redefined with ultrasound imaging. J Anat. 2005 June; 206(6): 525-534. 
chamada aréola. Contém também fibras musculares involuntárias, cuja contracção (por acção da oxitocina) provoca a erecção do mamilo.

Durante a gravidez, a aréola aumenta de tamanho e escurece. Após o período de lactação o grau de pigmentação vai diminuindo embora não retorne em absoluto à cor original.

$\mathrm{Na}$ aréola são ainda observáveis pequenas papilas com 1 ou 2 milímetros de diâmetro constituídas por uma glândula sebácea e algum tecido mamário, que correspondem às glândulas de Montgomery, que se hipertrofiam na gravidez e lactação e produzem secreções oleosas e antisépticas que se acredita serem protectoras da aréola e do mamilo.

$\mathrm{Na}$ altura do nascimento, os estrogénios maternos que atravessaram a placenta podem ser responsáveis por alguma hipertrofia da glândula mamária do recém-nascido, tanto em rapazes como em raparigas, podendo, por vezes, observar-se a excreção de algum leite, independentemente do seu tipo de alimentação ser de origem materna ou artificial. Passado o efeito dos estrogénios, a mama do bebé ficará espontaneamente em repouso.

Rara é a telarca prematura, uma variante da normalidade que consiste num aumento do tamanho da mama e que não deve ser confundida com a puberdade precoce. Ocorre em raparigas com menos de 2 anos de idade, pode ser uni ou bilateral ou até assimétrica e o seu tamanho ter flutuações. No entanto não coexistem outros sinais pubertários, a idade óssea é normal e os níveis de hormona luteínica não estão aumentados, permitindo fazer o diagnóstico diferencial. A telarca prematura é um processo benigno, que habitualmente desaparece antes dos $3 / 5$ anos, não está associado à amamentação e não constitui motivo para o desmame. ${ }^{8}$

Na puberdade, a elevação dos níveis séricos de estrogénio induz a proliferação celular com desenvolvimento de pequenas estruturas túbulo-alveolares nas extremidades dos ductos, que condiciona um aumento progressivo do tamanho das mamas, enquanto simultaneamente os canais galactóforos se ramificam e alongam. O início do desenvolvimento mamário pode ser assimétrico e acontecer meses antes numa mama em relação à outra. As diferenças de tamanho observáveis ficam a dever-se a variações na quantidade de tecido adiposo e não de tecido glandular. As mulheres com mamas pequenas podem amamentar sem problemas.

Numa mama em repouso funcional, os ácinos são praticamente inexistentes. Durante a gravidez ocorre uma significativa neoformação de ácinos, responsável pelo aumento de volume da glândula mamária. O tecido conjuntivo em redor das unidades secretoras é invadido por plasmócitos, linfócitos e eosinófilos. No estádio final da gestação, o desenvolvimento da mama é evidente e a secreção do colostro identificada pela maioria das grávidas (lactogénese I).

Não obstante, algumas mães lactantes negam ter sentido um significativo aumento mamário durante a gravidez. ${ }^{9}$

Após o parto e a dequitadura, o declínio rápido dos estrogénios (responsáveis pelo desenvolvimento dos ductos e deposição de gordura), seguido da diminuição gradual dos progestagéneos (responsáveis pelo desenvolvimento dos alvéolos e diferenciação das células secretoras), suspende o efeito inibidor da lactação, promovido pela placenta durante a gravidez. Cerca de 30 a 40 horas após o parto tem então início a secreção de leite (lactogénese II) com um pico, «subida de leite», por volta das 70 horas. Esta função endócrina é directamente dependente da interacção hormonal e independente da estimulação da mama.

A prolactina produzida pela adenohipófise e presente em níveis elevados pode então actuar junto dos receptores mamários e desencadear a produção. Um único tipo de células alveolares secreta os lípidos, proteínas e hidratos de carbono presentes no leite. De forma lenta, no intervalo das mamadas, a secreção vai preenchendo o lúmen dos alvéolos. No entanto, o leite armazenado não flui espontaneamente e depende de uma outra hormona que assegure um reflexo neurogénico de excreção. A oxitocina produzida pela neurohipófise é a responsável pela ejecção ou «descida do leite». A estimulação pelo bebé das múltiplas terminações nervosas presentes no mamilo produz impulsos sensitivos somáticos que são conduzidos ao hipotálamo e induz a rápida produção de oxitocina.

Por sua vez, o esvaziamento e a consequente diminuição da pressão intra-alveolar contribuem para que o reflexo neuro-endócrino desencadeie nova actividade secretora. A lactogénese III corresponderá depois à manutenção da secreção láctea e é já uma função au- 
tócrina, dependente da frequência e eficácia com que for removido o leite.

\section{CONTROLO DO VOLUME DE LEITE}

As principais hormonas que regulam a produção de leite são então a prolactina, a oxitocina e o FIL (factor inibidor da lactação). Tanto a prolactina como a oxitocina são segregadas na hipófise, em resposta à estimulação do mamilo. A primeira actua sobre as células secretoras da mama, estimulando a secreção de leite, ao passo que a segunda actua sobre as células mioepiteliais, provocando a sua contracção e a ejecção de leite.

\section{Prolactina}

O nível de prolactina aumenta de forma notável durante a gravidez embora a acção dos progestagéneos e estrogénios condicionem uma produção de leite quase nula. Durante o processo de amamentação, o nível basal de prolactina manter-se-á sempre elevado e aumentará ainda mais a cada vez que o bebé mamar. Cerca de 3 horas após a mamada, o nível de prolactina atinge o seu pico para ir baixando gradualmente. Se o bebé voltar a mamar antes de a hormona alcançar o seu nível basal, o novo pico de prolactina irá alcançar valores ainda mais altos. Por esta razão, dar de mamar frequentemente, ainda que de forma breve, estimula mais a produção de leite do que mamadas prolongadas.

No período nocturno, tanto os níveis basais como os picos de prolactina apresentam valores mais elevados, justificando a relevância das mamadas nocturnas para a manutenção da amamentação. Após alguns meses de amamentação, tanto o nível basal como os picos de prolactina são mais baixos, apesar de a quantidade de leite produzida ser maior. Ao que parece, a produção de leite dependerá mais de um controlo local que da produção de prolactina.

\section{Oxitocina}

A oxitocina é segregada por picos de alguns minutos. $\mathrm{O}$ reflexo de oxitocina, ou reflexo de ejecção do leite, pode ser desencadeado de forma espontânea, não sendo imprescindível a estimulação física da mama. Por vezes, um estímulo condicionado como ouvir o bebé chorar, olhar para o bebé ou pensar em dar de mamar é suficiente. Muitas mulheres referem este reflexo como «uma sensação de formigueiro» ou «pressão» na mama enquanto é visível o gotejar do leite. Algumas não conhecem esta sensação, ainda que amamentem sem dificuldades.

A insegurança ou o medo podem inibir temporariamente o reflexo de ejecção do leite e dificultar a amamentação, através de dois mecanismos: com a inibição directa do reflexo de oxitocina e a libertação de um antagonista, a adrenalina. Parece tratar-se de um mecanismo de cariz adaptativo típico dos mamíferos: com a adrenalina da fêmea em fuga, a inibir o reflexo de ejecção do leite protegendo instintivamente a cria. No entanto, a secreção de prolactina e a consequente produção de leite não são influenciadas pelo efeito temporário da adrenalina; logo que volte a estar tranquila, o leite voltará a fluir. Também para as mulheres, preocupações, como o medo de não ter leite suficiente, podem inibir a oxitocina e dificultar a lactação. Ao longo dos séculos, as mulheres amamentaram mesmo quando submetidas a perigos e preocupações extremas como a escravidão, a guerra, ou até a fome; no entanto, hoje em dia, facilmente se substitui o leite materno pelo artificial, por vezes fazendo recurso de amostras gratuitas de um qualquer pacote «oferta». Em muitas situações será o biberão e não a preocupação a dificultar a amamentação. ${ }^{10}$

\section{FIL (Factor Inibidor da Lactação)}

Tanto a oxitocina como a prolactina são transportadas no sangue e afluem simultaneamente a ambas as mamas. No entanto, ocasionalmente observamos mães que amamentam os seus filhos de uma única mama enquanto a outra permanece inactiva. Facto que fica a dever-se a um eficiente mecanismo de retro-controlo, de acção local e independente em cada uma das mamas. Durante muito tempo acreditou-se que este controlo local estava relacionado com a pressão do leite não extraído que comprimia os vasos sanguíneos, dificultando a passagem das hormonas e dos nutrientes necessários para a produção de leite. Hoje, o FIL é conhecido como o factor local responsável pelo controlo autócrino da glândula mamária. O FIL é um peptídeo identificado no leite humano e no de outros mamíferos. Quando o bebé mama, extrai o inibidor e desencadeia a produção de mais leite. Se, pelo contrário, não mamar ou mamar pouco, o inibidor permanece na mama e frena a produção. ${ }^{11}$ 
Através de medições seriadas do volume mamário foi possível demonstrar que o leite é produzido de forma contínua e que a velocidade da produção de leite é directamente proporcional à quantidade de leite extraído na mamada anterior. ${ }^{12}$

É desta forma que a produção de leite se adapta às necessidades do lactente, de uma mamada para a seguinte e separadamente para cada uma das mamas.

Depois dos seis meses de amamentação, a eficiência do tecido mamário para segregar leite aumenta, permitindo a manutenção da produção, ainda que as mamas aparentemente diminuam de volume. ${ }^{13}$

\section{CONTROLO DA COMPOSIÇÃO DO LEITE}

O teor de lípidos do leite materno aumenta paulatinamente à medida que decorre a refeição. O leite disponível no final pode conter 5 vezes mais lípidos do que o do início.

Ao observar as primeiras gotas de leite, algumas mulheres podem por essa razão acreditar ter o leite «aguado» não obstante o leite final ser rico em gordura.

À medida que o tempo for passando, o leite não retirado volta a ser diluído por leite recentemente produzido.

A concentração média de lípidos obtidos de cada vez é directamente proporcional à quantidade de leite extraído na mamada anterior acrescida da quantidade extraída na actual e inversamente proporcional ao tempo decorrido entre elas.

A duração das mamadas, pelo contrário, não está relacionada com a quantidade de leite ingerido, nem estatisticamente correlacionada com a concentração de lípidos. O volume de leite ingerido por unidade de tempo varia muito de um lactente para outro, de uma mamada para outra e ao longo de uma mesma mamada.

Se o volume é proveniente das duas mamas, mais dificilmente o bebé obterá o leite final da segunda, pelo que terá tomado duas «doses» de leite inicial e apenas uma de leite final e que corresponderá a uma menor concentração média de lípidos no total de leite ingerido.

\section{GESTÃo PELO CLIENTE (BEBÉ)}

O lactente pode regular a composição do leite se puder modificar três factores: o tempo entre as sucessivas mamadas, o volume de leite ingerido de cada vez e se obtém leite de uma só mama ou das duas (Figura 2).

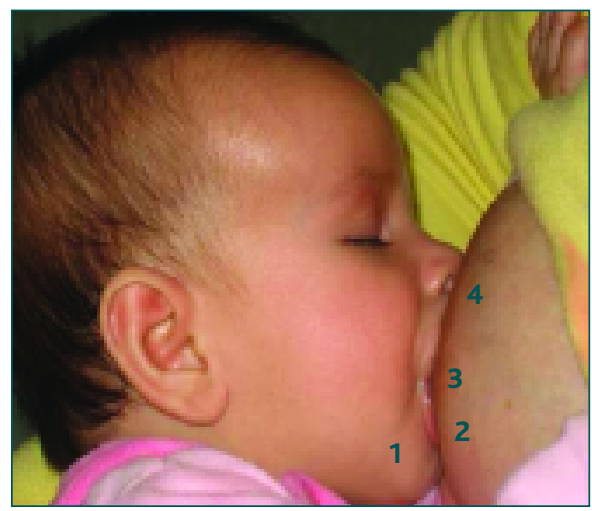

Figura 2. Sinais a observar: 1/ queixo junto à mama, 2/lábio inferior evertido, 3/boca bem aberta, 4/maior porção da aréola visível acima do lábio superior.

(Cortesia de ARS Algarve)

Não se sabe se o lactente é capaz de regular também outros aspectos da composição do leite.

Se a ingestão for fixa, aqueles que ingerirem menos gorduras obterão em troca mais proteínas e lactose.

Nalgumas mulheres a concentração de proteínas é muito diferente entre uma mama e a outra, o que pode ter alguma relação com a preferência que alguns lactentes desenvolvem por uma delas.

Quando se limita o tempo (por exemplo 15 minutos) e se transfere o bebé arbitrariamente da primeira para a segunda mama antes que ele tenha terminado, oferece-se-lhe o leite inicial e menos calórico de ambas as mamas, não tendo acesso ao leite final rico em gorduras e calorias.

Nalguns casos, para suprir o valor calórico do leite final perdido, o volume necessário supera a capacidade gástrica do lactente. O bebé tem fome, mas simplesmente não tem espaço para mais leite ficando habitualmente insatisfeito e choroso. Ao receber menos lípidos (do leite final), ingere mais proteínas e mais lactose, o que pode ocasionar uma intolerância parcial à lactose por sobrecarga. A lactose não digerida fermenta no tubo digestivo, produzindo gases, cólicas e fezes ácidas e muito líquidas (diarreia osmótica).

Woolridge e Fisher descreveram cinco lactentes que apresentavam estes sintomas e que regressaram à normalidade dizendo-se simplesmente à mãe que deixasse o seu filho mamar da primeira mama enquanto ele quisesse antes de lhe oferecer a segunda. ${ }^{14} \mathrm{Num}$ estu- 
do posterior, Woolridge e Fisher tentaram reproduzir estes sintomas num grupo de voluntários saudáveis, pedindo às mães que limitassem a sucção da primeira mama a dez minutos. Tal como esperavam, a concentração de lípidos obtida pelo lactente de uma única vez era muito inferior com esta limitação; mas observaram com surpresa que, ao longo de 24 horas, os lactentes conseguiam obter uma quantidade de lípidos normal, com base na modificação dos outros factores: a frequência das mamadas e o mamar de cada vez numa das mamas ou nas duas. ${ }^{15}$

Parece, portanto, que a maioria dos lactentes (mas não todos), em face da fixação arbitrária do tempo de mamar, é ainda assim capaz de obter leite com a composição desejada modificando outros factores. ${ }^{16}$ Infelizmente, durante o século passado tornou-se moda limitar simultaneamente os três mecanismos de controlo do lactente (uma ou duas mamas, frequência e tempo a mamar), com regras do tipo «dez minutos de cada mama a cada quatro horas». Este procedimento condiciona a auto-regulação e o leite obtido pode ter uma composição muito diferente da desejada/necessária.

\section{AMAMENTAÇÃO}

De acordo com os estudos observacionais mais recentes, o RN de termo, saudável, quando mantido em posição ventral sobre o abdómen da mãe, desloca-se de forma reflexa e adapta-se autónoma e perfeitamente a uma das mamas. Segundo Colson, ${ }^{17,18}$ quando assim colocado, o bebé sente-se como que "projectado» para o corpo da mãe onde, por reflexo anti-gravítico, obtém a estabilidade das extremidades distais que viabiliza $o$ controlo da cabeça.

Instintos comportamentais e programação neuro-endócrina são observáveis quando o bebé está junto da mãe: o seu SNC liberta oxitocina, produzindo uma resposta vagal, relaxamento do tónus, comportamentos e reflexos de alimentação; pelo contrário, se separado da mãe, a resposta simpática, com libertação de cortisol, aumenta o tónus e o stress, que desencadeiam o choro.

Em sintonia com o bebé, a mãe desencadeia o reflexo de oxitocina e expulsa o leite para o lúmen dos alvéolos e deles para os ductos e para a boca do bebé.

Numa boa adaptação do bebé à mãe, os seus lábios, a língua, o palato e a musculatura lateral da bochecha rodeiam o tecido mamário. A saída do leite é auxiliada pelas ondas peristálticas que percorrem toda a língua, premindo o mamilo contra o palato. Atribui-se inclusive a este trabalho muscular com movimentos anteroposteriores repetidos, a estimulação do crescimento da mandíbula com correcção do retrognatismo fisiológico do RN. ${ }^{19}$

Um bom posicionamento permite ao bebé obter uma boa transferência de leite e à mãe amamentar sem dor.

Ainda segundo Colson ${ }^{17,18}$ os RN mantidos em contacto sobre o abdómen materno conseguem em $90 \%$ dos casos abrir bem a boca e inserir além do mamilo uma boa parte da aréola sem qualquer intervenção externa.

Têm sido valorizados como preditores do sucesso da amamentação alguns sinais observáveis considerados de «uma eficaz adaptação à mama», e que se podem resumir da seguinte forma: mento do lactente junto à mama, com ângulo significativo de abertura da boca $\mathrm{e}$ lábio inferior evertido (pela protrusão da língua). É também desejável uma relativa assimetria do posicionamento, devendo a aréola ser mais visível acima do lábio superior que abaixo do inferior (Figura 3).

Quando adaptado de forma incorrecta, é frequente que o mamilo fique pouco alongado e seja pressionado contra o palato duro, que o molda. Nesta situação é comum a mãe referir dor e/ou fissuras. ${ }^{5}$

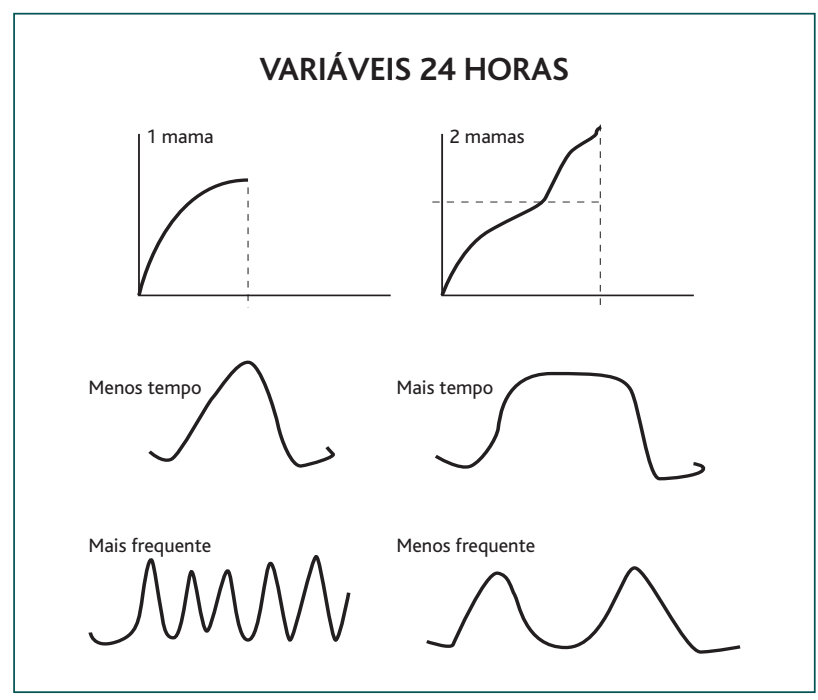

Figura 3. Factores modificáveis na ingesta Adelaide Orfão/2009. 


\section{CONCLUSÃO}

Conhecer a anatomia e a fisiologia da lactação é fundamental para o aconselhamento e para a resolução personalizada de problemas.

O lactente pode regular a composição do leite se puder modificar três factores: o tempo entre as sucessivas mamadas, o volume de leite ingerido de cada vez e se obtém leite de uma só mama ou das duas. Pelo que importa interferir menos e ponderar a introdução de substitutos do leite materno.

Confiantes neste mecanismo de auto-regulação, uma vez que as necessidades variam de bebé para bebé e a resposta materna está dependente de múltiplos factores, mães e filhos (e por inerência os profissionais) correm menos riscos quando permitem que seja o lactente a gerir o seu próprio aporte.

Defensável é ainda o início precoce desta prática, pois, segundo Pereira, existe uma associação entre uma boa adaptação logo na primeira mamada e o sucesso do AM exclusivo, do AM complementado e do AM total durante o primeiro ano de vida. ${ }^{20}$

\section{REFERÊNCIAS BIBLIOGRÁFICAS}

1. Vinagre RD, Diniz EM, Vaz FA. Leite humano: um pouco de sua história. Pediatria (São Paulo) 2001; 23(4):340-5.

2. Branco MJ, Nunes B. Uma observação sobre aleitamento materno: Relatório. Lisboa: ONSA / INSA; 2003.

3. Sandes AR, Nascimento C, Figueira J, Gouveia R, Valente S, Martins $S$, et al.Aleitamento materno: prevalência e factores condicionantes. Acta Med Port 2007 Maio-Jun; 20 (3): 193-200.

4. Evolução da duração do aleitamento materno em Portugal. Disponível em: http://www.amamentar.net/Notícias/tabid/150/articleType/ArticleView/articleld/3/Default.aspx [acedido em 04/09/2009]..

5. Orfão A. Avaliação dos primeiros 1000 casos do Cantinho da Amamentação. Revista APEO 2006; 6.

6. Galvão DG.Amamentação Bem sucedida:Alguns factores determinantes. Loures: Lusociência; 2006.
7. King FS. Como ajudar as mães a amamentar. Londrina: Universidade Estadual de Londrina; 1991.

8. Parks JS, Felner El. In: Kliegman RM, Behrman RE, Jenson HB, Stanton BF, editors. Nelson Textbook of Pediatrics. 18th ed. Philadelphia: Saunders; 2007. p. 2314.

9. Lawrence RA, Lawrence RM. Breastfeeding: a guide for the medical profession. 6th ed. New York: Elsevier Mosby; 2005.

10. González C. Manual Prático do Aleitamento Materno. Lisboa: Associação Mama Mater; 2008. p. 15.

11. Daly SE, Hartmann PE. Infant demand and milk supply. Part 2: the short-term control of milk synthesis in lactating women. J Hum Lact 1995 Mar; 11 (1) :27-37.

12. Daly SE, Kent JC, Owens RA, Hartmann PE. Frequency and degree of milk removal and the short-term control of human milk synthesis. Exp Physiol 1996 Sep; 81 (5): 861-75.

13. Kent JC, Mitoulas L, Cox DB, Owens RA, Hartmann PE. Breast volume and milk production during extended lactation in women. Exp Physiol 1999 Mar; 84 (2): 435-47.

14. Woolridge MW, Fisher C. Colic, «overfeeding», and symptoms of lactose malabsorption in the breast-fed baby: a possible artifact of feed management? Lancet 1988 Aug 13; 332 (8607): 382-4.

15. Britton JR. Discordance of milk protein production between right and left mammary glands. J Pediatr Gastroenterol Nutr 1986 Jan; 5 (1): 127-9.

16. González C. Manual Prático do Aleitamento Materno. Lisboa: Associação Mama Mater; 2008. p. 19.

17. Colson S. Maternal breastfeeding positions: have we got it right? (1). Pract Midwife 2005 Nov; 8 (10): 24-7.

18. Colson S. Maternal breastfeeding positions: have we go it right? (2). Pract Midwife 2005 Dec; 8 (11): 29-32.

19. Carvalho GD. Enfoque odontológico. In: Amamentação: bases científicas. 2ed. Rio de Janeiro: Guanabara Koogan; 2005. p. 89-106.

20. Pereira A. Importância da correcção da pega no sucesso da amamentação. Lisboa: Lusociência; 2006.

Conflitos de Interesse: não assinalados

\section{ENDEREÇO PARA CORRESPONDÊNCIA}

Maria Adelaide Orfão

E-mail: adelaideorfao@dgs.pt 


\section{ABSTRACT}

Breast size is related to the amount of mammary tissue and to the deposits of intra and interlobular fat, but doesn't reflect its functional ability.

Prolactin, oxytocin and feedback inhibitor of lactation are the main hormones that regulate milk production. Concerns, such as fear of not having enough milk, inhibit prolactin and oxytocin and hinder lactation.

The baby can regulate milk composition if he can modify three factors: time between feeds, the amount of ingested milk in each meal and free access to all the milk produced by one or both breasts.

According to recent observational studies, when placed on the mother's abdomen, the term healthy newborn moves reflexively, and easily adapts to one of the breasts without causing any pain or discomfort. This autonomous behaviour of the baby seems to be associated to a higher degree of satisfaction of the mother and to an increased duration of breastfeeding.

Attending to the particularity of each mother-baby dyad, client oriented management seems to be the key-answer to a successful breastfeeding.

Keywords: Anatomy; Phisiology; Mammary Gland; Lactation Management. 